\title{
O ACESSO À UNIVERSIDADE FEDERAL DE GOIÁS NO CONTEXTO DE SUA EXPANSÃO
}

\section{ACCESS TO THE FEDERAL UNIVERSITY OF GOIÁS IN THE CONTEXT OF ITS EXPANSION}

\section{ACCESO A LA UNIVERSIDAD FEDERAL DE GOIÁS EN EL CONTEXTO DE SU EXPANSIÓN}

\author{
ROSA, Chaiane de Medeiros \\ chaianemr@hotmail.com \\ Universidade Estadual Paulista "Júlio de Mesquita Filho" - Campus Araraquara \\ https://orcid.org/0000-0001-8609-3487 \\ RIBEIRO, Ricardo \\ despertarosol@gmail.com \\ Universidade Estadual Paulista "Júlio de Mesquita Filho" - Campus Araraquara \\ http://orcid.org/0000-0002-7478-4835
}

\begin{abstract}
RESUMO A Universidade Federal de Goiás foi criada em 1960, e, desde então, passou por processo de expansão e interiorização, ampliando o seu atendimento. Contudo, a maior fase de sua expansão ocorreu nos anos 2000, especialmente a partir do Reuni. Diante disso, este estudo tem como objetivo compreender o acesso à essa instituição, no contexto de sua expansão. Para a realização deste estudo, foi desenvolvida uma pesquisa documental, baseada em registros estatísticos disponibilizados pela Pró-Reitoria de Graduação da instituição pesquisada. Esses dados foram com base em pesquisa bibliográfica, fundamentada em aporte teórico sobre a temática em estudo. Como resultado, constatou-se que a UFG se destaca pela qualidade dos cursos oferecidos; pela expansão e interiorização, mas enfrenta o desafio da permanência dos alunos ingressantes.
\end{abstract}

PALAVRAS-CHAVE: Reuni. Acesso. Expansão. Universidade Federal de Goiás.

ABSTRACT The Federal University of Goiás was created in 1960, and since then, has undergone expansion and internalization, expanding its service. However, the largest phase of its expansion occurred in the 2000s, especially since the Reuni. Given this, this study aims to understand the access to this institution, in the context of its expansion. For the accomplishment of this study, a documentary research was developed, based on statistical records made available by the Pro-Rectory of Graduation of the research institution. These data were based on bibliographical research, based on a theoretical contribution on the theme under study. As a result, it was verified that the UFG stands out for the quality of the courses offered; by the expansion and interiorization, but faces the challenge of the stay of incoming students. 
KEYWORDS: Reuni. Access. Expansion. Goiás Federal University.

RESUMEN La Universidad Federal de Goiás fue creada en 1960, y desde entonces ha pasado por un proceso de expansión e internalización, ampliando su servicio. Sin embargo, la mayor fase de su expansión se produjo en la década de 2000, especialmente desde Reuni. Ante esto, este estudio tiene como objetivo comprender el acceso a esta institución, en el contexto de su expansión. Para la realización de este estudio, se desarrolló una investigación documental, basada en registros estadísticos disponibles por el decano de pregrado de la institución investigada. Estos datos se basaron en la investigación bibliográfica, basada en el soporte teórico sobre el tema en estudio. Como resultado, se descubrió que UFG destaca por la calidad de los cursos ofrecidos; expansión e internalización, pero enfrenta el desafío de la permanencia de nuevos estudiantes.

PALABRAS CLAVE Reuni. Acceso. Expansión Universidad Federal de Goiás.

\section{INTRODUÇÃO}

A UFG foi criada em 14 de dezembro de 1960. Mas sua descentralização e processo de expansão e interiorização são decorrentes da necessidade de integrar e desenvolver os municípios do estado de Goiás. Foi então, que, na década de 1980, a universidade deu início à interiorização dos seus cursos, primeiramente em Jataí (1980), Catalão (1983), e posteriormente na Cidade de Goiás (1990).

Durante uma década, predominaram na instituição as atividades de ensino, principalmente por falta de condições efetivas para a realização de pesquisa e extensão. A partir da década de 1970, a universidade buscou articular, de fato, ensino, pesquisa e extensão. Mas, foi nos anos 1990 que se consolidaram, efetivamente, a pesquisa, a pós-graduação e as atividades de extensão universitária, o que se tornou possível em razão da qualificação do corpo docente e da produção científica realizada no âmbito da instituição. Também na década de 1990 a universidade passou por um processo significativo de expansão (UFG. Plano de Desenvolvimento Institucional, 2011/15). Mas o grande desenvolvimento da UFG ocorreu nos anos 2000, motivado sobretudo pelo Programa de Apoio a Planos de Reestruturação e Expansão das Universidades Federais (Reuni), instituído pelo Decreto $n^{\circ} 6.096$ de 2007. 
Diante disso, este artigo tem como objetivo compreender o acesso à essa instituição, no contexto de sua expansão, promovida principalmente a partir do Reuni. E estudar o acesso é relevante, pois,

[...] acredita-se que a questão da garantia do acesso à educação superior relaciona-se, ainda, com o acesso à bens que extrapolam aos limites físicos das instituições de ensino, como o mercado de trabalho. Desse modo, o acesso, ao possibilitar melhor capacitação para o emprego, faz com que uma grande parcela de indivíduos, antes excluída social e economicamente, saia da zona de extrema pobreza e avance, melhorando sua qualidade de vida, podendo, assim, participar de forma mais efetiva de diversas dimensões sociais (ROSA; GONÇALVES, 2016, p. 189).

Para a realização deste estudo, foi desenvolvida uma pesquisa com abordagem quanti-qualitativa. Isso porque articula a dimensão quantitativa, que é marcada pelo uso da quantificação, seja na coleta de informações ou no tratamento das mesmas, por meio de técnicas estatísticas (RICHARDSON, 1989), com a dimensão qualitativa, que tem como foco a interpretação, ao invés da quantificação (CASSEL; SYMON, 1994).

$\mathrm{Na}$ dimensão quantitativa, foram analisados documentos, sob a forma de registros estatísticos, disponibilizados em planilhas do Excel pela Pró-Reitoria de Graduação (Prograd) da instituição pesquisada. A partir dessas fontes, foi possível extrair dados como: cursos e vagas ofertadas por regional e área do conhecimento; oferta de vagas e número de ingressantes; cursos mais e menos concorridos; e cursos com maior e menor nota mínima para ingresso. Esses dados foram interpretados e articulados com suportes teóricos. A análise e interpretação ocorreram com o aporte da pesquisa bibliográfica, feita a partir do levantamento de referências teóricas já analisadas, e publicadas por meios escritos e eletrônicos, como livros, artigos científicos, e mais (FONSECA, 2002). É a pesquisa bibliográfica, pois, que garante o embasamento teórico do trabalho.

\section{EXPANSÃO E OFERTA}

O acesso à educação superior é um desafio no Brasil. De acordo com o Censo da Educação Superior de 2015, a taxa bruta de acesso à educação superior 
é de $34,2 \%$ e a taxa líquida de $17,7 \%$ (INEP, 2017c). No mais, estudo de Rosa (2016) aponta que, a média de anos de estudo de pessoas com idade entre 18 e 24 anos, que é a idade regular de estar na educação superior, é de 9,8 anos, abaixo dos 12 anos, média de tempo de escolarização de quem concluiu o ensino médio e está apto a ingressar na educação superior. Outro dado considerável é que 30,8\% das pessoas nessa faixa etária possui menos de 11 anos de escolarização. Significa, pois, que há um elevado número de pessoas excluídas desse nível de ensino.

A partir dos anos 2000, uma série de políticas foram criadas no sentido de reverter esse quadro, e estimular a expansão da oferta e permanência na educação superior, especialmente na rede pública. Nesse contexto, destacam-se os seguintes programas: o Fundo de Financiamento do Estudante de Ensino Superior (Fies), criado em 2001, voltado para a concessão de financiamento a estudantes de instituições privadas; o Programa Universidade para Todos (Prouni), criado em 2005, com a finalidade de ofertar bolsas de estudos para estudantes de instituições privadas; a expansão da educação à distância por meio da Universidade Aberta do Brasil (UAB), criada em 2006, com o escopo de expandir e interiorizar a oferta de cursos e programas de educação superior; o Reuni, criado em 2007, com o objetivo de criar condições para ampliação do acesso e permanência na educação superior; a expansão da educação profissional e tecnológica pela criação da Rede Federal de Educação Profissional, Científica e Tecnológica e dos Institutos Federais de Educação, Ciência e Tecnologia (IFs) em 2008; o Plano Nacional de Assistência Estudantil (Pnaes), criado em $2010 \mathrm{com}$ a finalidade de ampliar as condições de permanência na educação superior; e a Lei $n^{0} 12.711$ de 2012, a lei de cotas, que estabelece reserva de vagas no acesso à educação superior para minorias étnicas e sociais da população brasileira.

No que diz respeito à expansão das instituições públicas, o programa de maior impacto em termos de expansão da oferta foi o Reuni, a partir do qual as universidades federais foram convidadas a elaborar seus projetos de expansão. $O$ Plano de Reestruturação e Expansão da UFG foi aprovado em 2008. 
Como resultado do Reuni na UFG, a universidade passou por uma franca expansão, que pode ser verificada pelo aumento do número de cursos:

\section{Gráfico 01: Evolução do total de cursos ofertados por regional - UFG - 2006/2016}

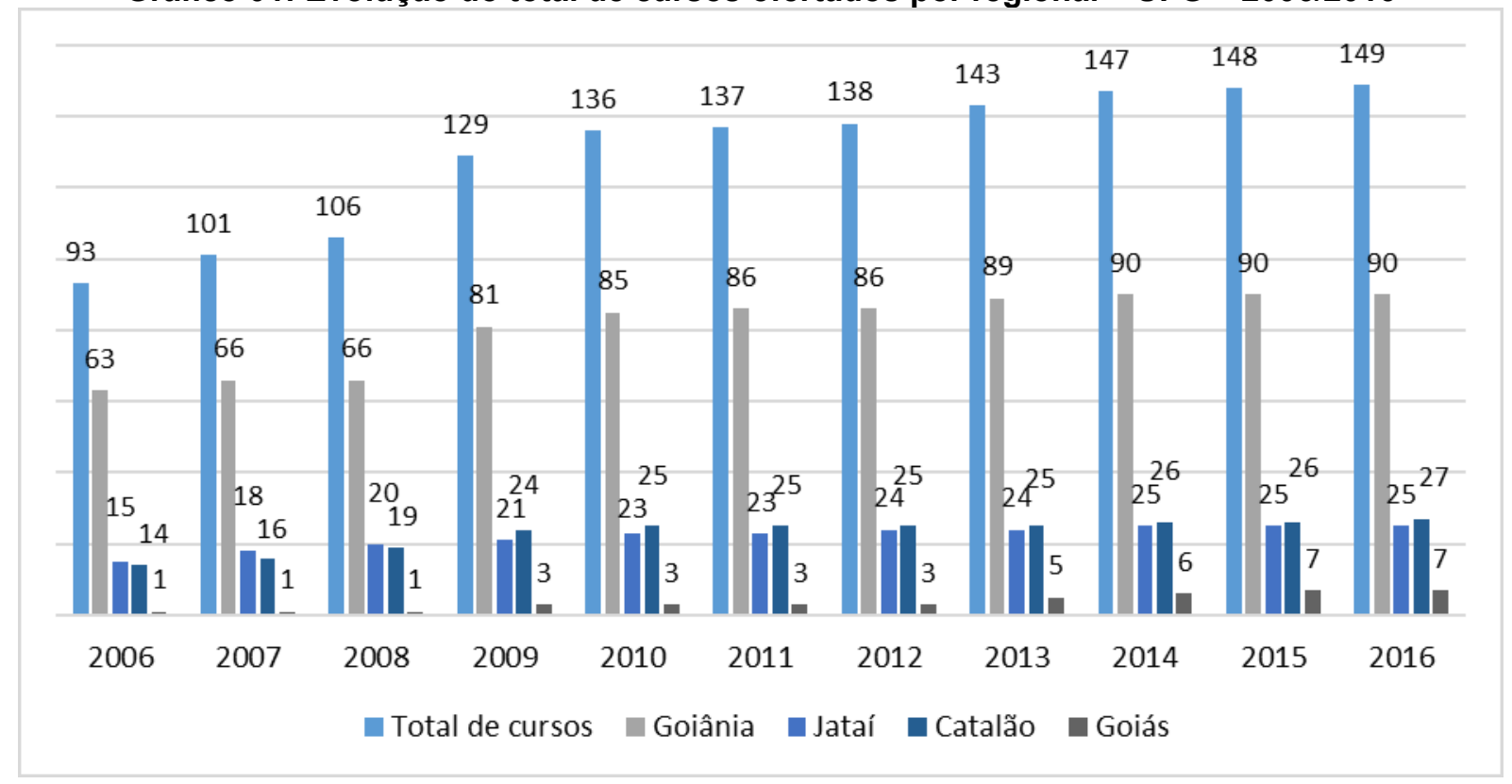

Fonte: A autora.

Em 2006, a universidade oferecia 93 cursos e em 2016 esse número chegou a 149, o que representa um crescimento de $60,2 \%$. Em Goiânia, o número de cursos passou de 63 para 90 , um aumento de $42,8 \%$; em Jataí de 15 para 25 cursos, uma ampliação de 66,6\%; em Catalão de 14 para 27, uma elevação de 92,8\%, e em Goiás de 1 para 7 , um crescimento de $600 \%$. Como se vê, a maior ampliação da UFG ocorreu nas regionais localizadas no interior do estado.

No total, em 2016, a oferta na UFG foi de 149 cursos em todas as suas regionais. Em Goiás foram ofertados 7 cursos (4,7\%); em Jataí, 25 (16,78\%); em Catalão, 27 (18,11\%); e em Goiânia, 90 (60,40\%). Portanto, 60,40\% dos cursos foram em Goiânia e 39,6\% no interior. Essa distribuição dos cursos foi acompanhada pela oferta de vagas, haja vista que, do total de 6.840 vagas ofertadas em 2016, 4.240 (61,99\%) estavam na capital, e 2.600 (38,01\%) no interior, como se pode ver no gráfico abaixo: 
Gráfico 02: Evolução do total de vagas ofertadas por região - UFG - 2006/2016

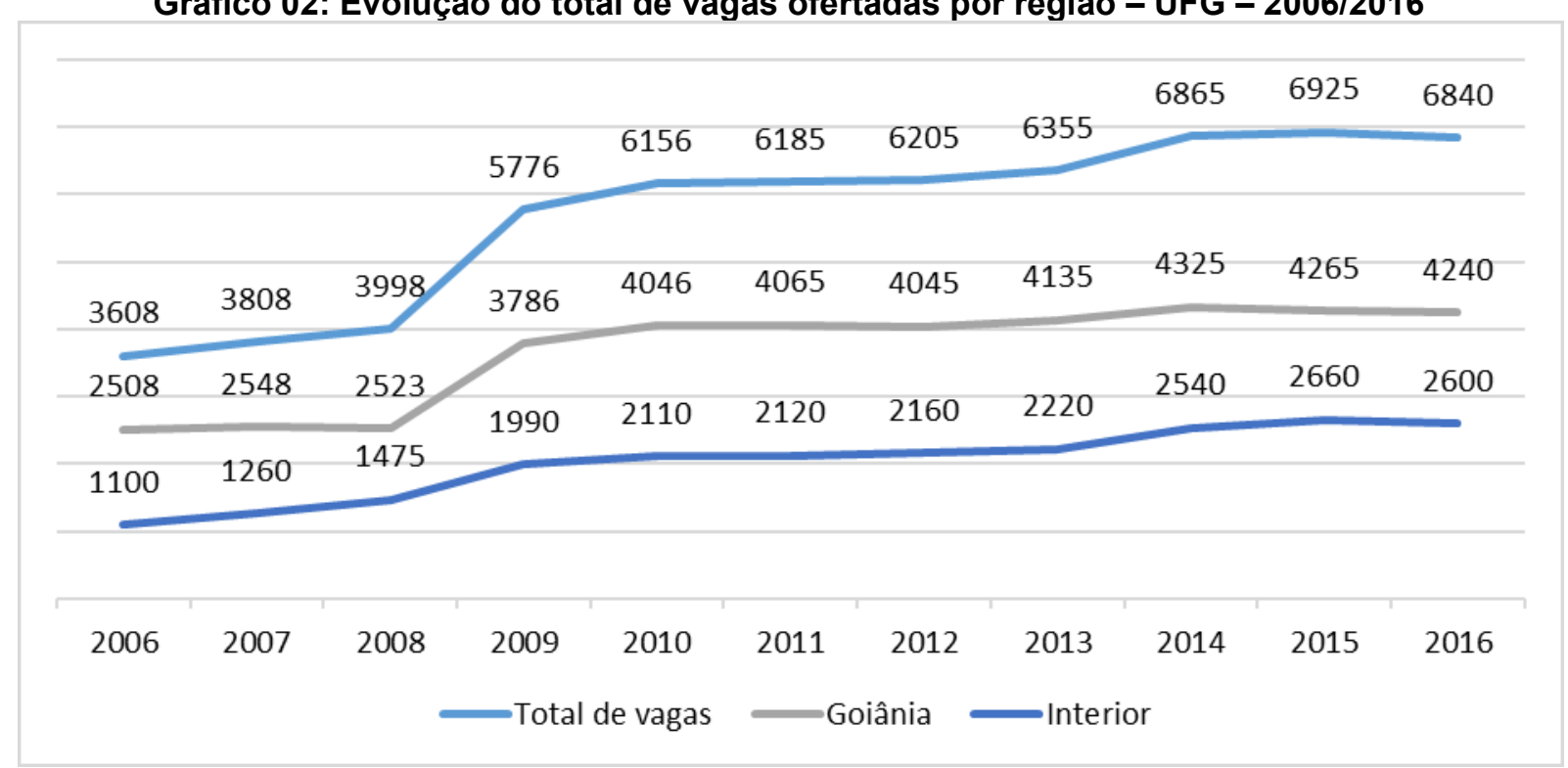

Fonte: A autora.

Em 2006, a UFG ofertou 3.618 vagas em todas as regionais, e, em 2016, 6.840 vagas, o que representa um crescimento de $89,05 \%$. Na regional Goiás, a oferta passou de 60 para 410 vagas, um aumento de 583,3\%. Em Catalão, as vagas passaram de 500 para 1.110, o que representa uma elevação de 122\%. Em Jataí, a oferta passou de 550 para 1.080 vagas, um aumento de $96,36 \%$. E na regional Goiânia a oferta foi ampliada de 2.508 para 4.240, o que consiste em uma elevação de $69,05 \%$. Com base nesses dados, depreende-se que a maior ampliação da oferta de vagas ocorreu nos campi situados no interior do estado. Porém, não se pode desconsiderar a expansão que ocorreu na capital.

$O$ foco no interior pode se explicar pelas políticas voltadas para a interiorização das oportunidades educacionais. A partir dos anos 2000,

\footnotetext{
A preocupação não apenas com a expansão, mas com a interiorização e a desconcentração das oportunidades de acesso à educação superior, é justificada a partir do quadro de concentração da oferta desse nível de ensino, visto que sua distribuição não se faz de forma homogênea e equilibrada em todos os estados e regiões do país (ROSA; GONÇALVES, 2016, p. 186).
}

Esse quadro de interiorização da UFG, portanto, reflete um panorama nacional. No Brasil, do total das 2.364 instituições de educação superior em 2015, 
846 são na capital (35,8\%) e 1.518 no interior (64,2\%). Considerando especificamente a rede pública brasileira, do total de 295 instituições, 98 estão na capital $(33,2 \%)$, e a maior parte, 197 , está no interior do país $(66,8 \%)$. Já quando se verifica apenas as instituições federais, entre as quais estão as universidades e os IFs, há uma inversão nesse quadro, sendo que, do total de 107 instituições, 64 estão na capital $(59,8 \%)$ e 43 no interior $(40,2 \%)$.

A maior parte das instituições federais de educação superior estão localizadas nas capitais, o que pode se explicar por se tratarem de instituições de grande porte, com oferta de imensa variedade de cursos, que se compõem de grande estrutura física e humana para atender aos estados, de forma geral. No caso da esfera federal, a interiorização é mais atribuída aos IFs, que são instituições menores, mais disseminadas nas regiões interioranas, com cursos voltados para as potencialidades das regiões onde são criados. Nesse sentido, a UFG se distingue nesse quadro das instituições federais com uma marca forte de interiorização por ser formada por quatro regionais, apenas uma delas situados na capital de Goiás, e as demais localizadas no interior do estado.

Em Goiás, das 85 instituições de educação superior, 27 estão na capital $(31,8 \%)$ e 58 no interior (68,2\%). Na esfera pública, das 8 instituições existentes no estado, 3 estão na capital $(37,5 \%)$ e 5 no interior (62,5\%). Já na esfera pública federal, em Goiás há 3 instituições, quais sejam: UFG, Instituto Federal de Educação, Ciência e Tecnologia Goiano (IF Goiano) e Instituto Federal de Educação, Ciência e Tecnologia de Goiás (IF Goiás). Todas essas instituições, apesar de terem seus campi sede em Goiânia, possuem campi no interior do estado. A UFG possui 3 regionais no interior (Catalão, Jataí e Goiás); o IF Goiano possui 13 campi no interior (Campos Belos, Catalão, Ceres, Cristalina, Hidrolândia, Ipameri, Iporá, Morrinhos, Posse, Rio Verde, Trindade, Urutaí e Rede Arco Norte), e o IF Goiás possui 12 campi fora da capital (Águas Lindas, Anápolis, Aparecida de Goiânia, Cidade de Goiás, Formosa, Inhumas, Itumbiara, Jataí, Luziânia, Senador Canedo, Uruaçu e Valparaíso). Portanto, ao todo, as três instituições federais de educação superior do estado de Goiás estão disseminadas por todo o estado, com 28 unidades descentralizadas da capital. 
Essa interiorização é de fundamental importância, visto que, de acordo com o Brasil (2015),

O desenvolvimento de uma região está diretamente ligado aos investimentos locais. O incentivo à educação, principalmente a superior, leva ao local de implementação um crescimento acelerado. [...] Ao mesmo tempo, os egressos do ensino médio sem opções de educação superior em sua região tendem a migrar, muitas vezes em caráter definitivo, para locais onde a oferta é mais ampla e diversificada. A região abandonada perde a oportunidade de fixar profissionais altamente qualificados e os estudantes sem condições financeiras de migrar para as regiões mais propícias perdem a oportunidade de se qualificar. Assim, a interiorização da oferta de educação superior é essencial para combater o desequilíbrio no desenvolvimento regional e atingir estudantes sem condições de se deslocar para outras regiões (BRASIL, 2015, p. 20).

Considerando as áreas de conhecimento, os cursos da UFG se distribuem da seguinte maneira:

Gráfico 03: Número de cursos por área do conhecimento por regional - UFG - 2016

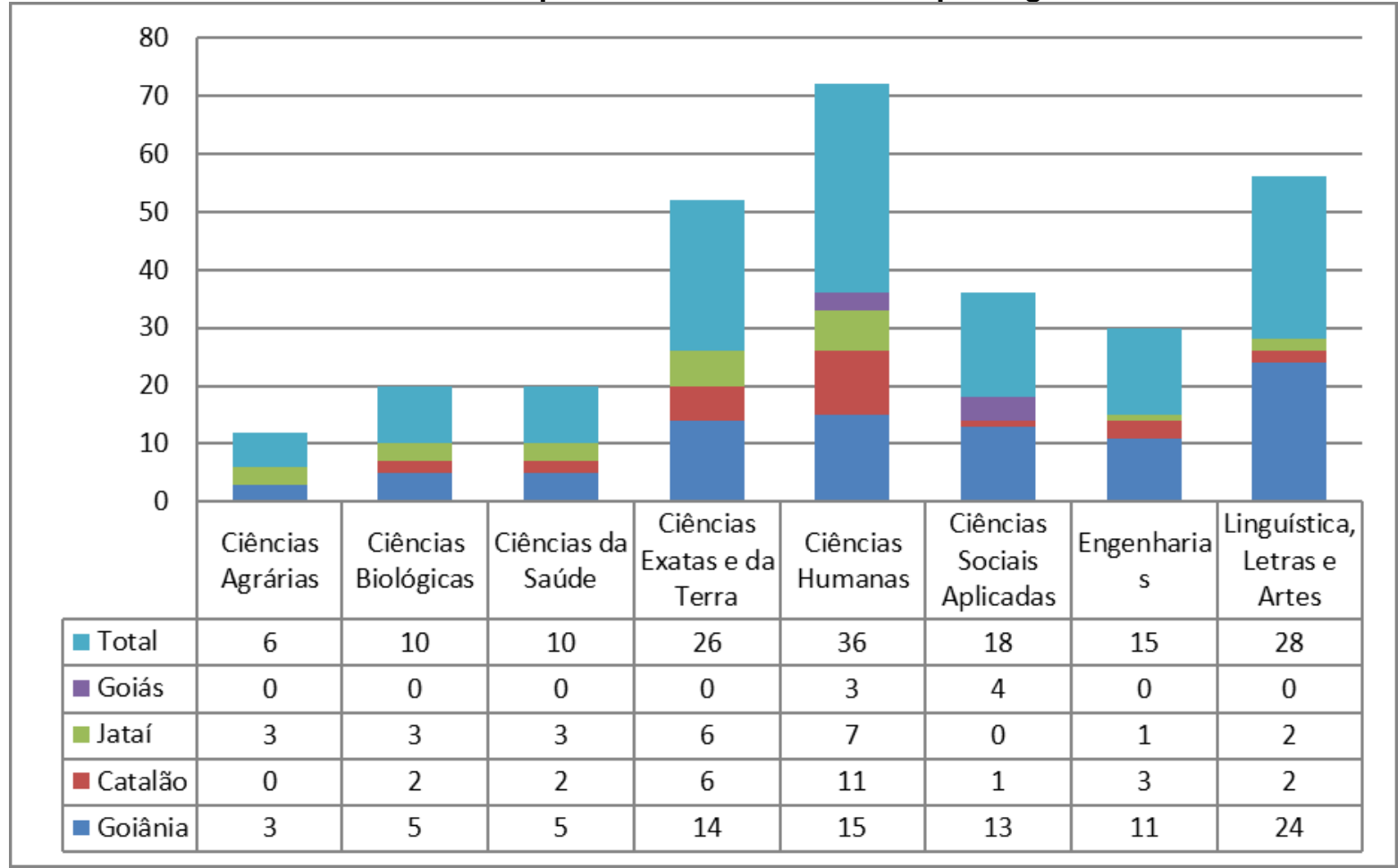

Fonte: A autora.

Como evidenciado no gráfico acima, na cidade de Goiás, há oferta de cursos apenas nas áreas de Ciências Sociais Aplicadas (4) e Ciências Humanas (3). Em 
Jataí, o predomínio é de cursos nas áreas de Ciências Humanas (7) e Ciências Exatas e da Terra (6), seguidos de cursos nas áreas de Ciências Agrárias (3), Ciências Biológicas (3), Ciências da Saúde (3), Linguística, Artes e Letras (2) e Engenharias (1). Em Catalão, seguindo a mesma tendência de Jataí, a maior parte dos cursos são na área de Ciências Humanas (11), Ciências Exatas e da Terra (6), e na sequência aparecem os cursos na área de Engenharias (3), Linguística, Letras e Artes (2), Ciências Biológicas (2) e Ciências da Saúde. Já em Goiânia o predominam cursos na área de Linguística, Letras e Artes (24), seguidos dos cursos nas áreas de Ciências Humanas (15), Ciências Exatas e da Terra (14), Ciências Sociais Aplicadas (13), Engenharias (11), Ciências Biológicas (5), Ciências da Saúde (5) e Ciências Agrárias (3).

No quadro geral da UFG, a maioria dos cursos ofertados é na área de Ciências Humanas (36), seguida da área de Linguística, Letras e Artes (28) e Ciências Exatas e da Terra (26). Depois aparecem os cursos de Ciências Sociais Aplicadas (18), Engenharias (15), Ciências Biológicas (10), Ciências da Saúde (10) e, por fim, Ciências Agrárias (6). Entretanto, quando se considera a quantidade de vagas ofertadas em cada área do conhecimento, o maior número de cursos por área do conhecimento não corresponde à maior oferta de vagas nas mesmas.

Gráfico 04: Número de vagas ofertadas por área do conhecimento - UFG - 2016

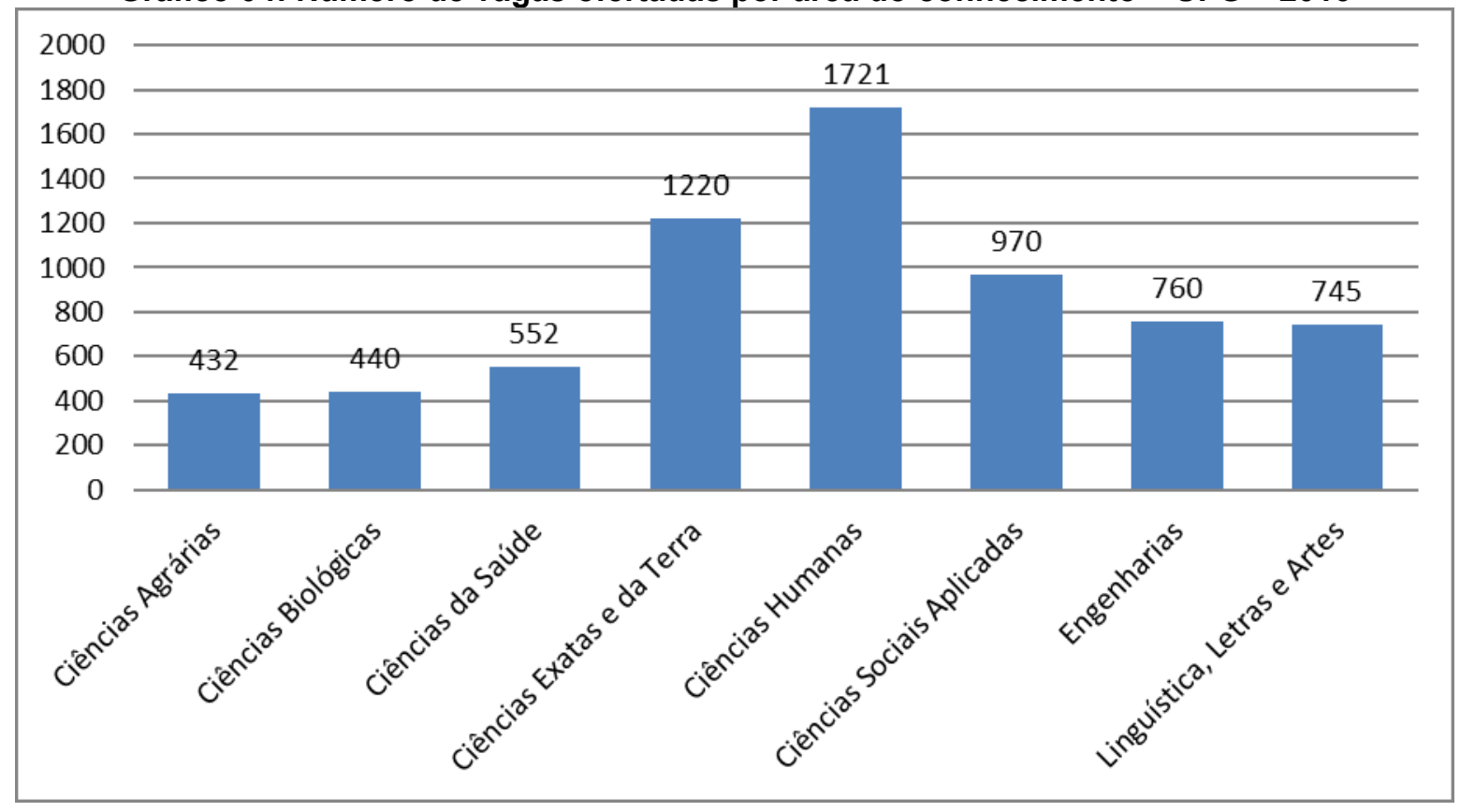


Fonte: A autora.

Conforme apresentado no gráfico acima, apenas na área de Ciências Humanas, que é a maior em oferta de cursos, também é a mais representativa em termos de oferta de vagas (1.721). A segunda maior oferta de vagas é na área de Ciências Exatas e da Terra (1.220), seguida das áreas de Ciências Sociais Aplicadas (970), Engenharias (760), Linguística, Letras e Artes (745), Ciências da Saúde (552), Ciências Biológicas (440) e Ciências Agrárias (432).

De acordo com Barros (2015), a concentração de estudantes em algumas áreas específicas,

\footnotetext{
Por um lado, isso significa que enquanto algumas áreas consideradas estratégias para o país ainda enfrentam o problema da mão de obra qualificada, outras colocam cada vez mais gente no mercado de trabalho; e, por outro, retratam que os cursos que oferecem mais vagas, geralmente, são programados para absorver uma grande parcela dos candidatos ao Ensino Superior [...] (BARROS, 2015, p. 364).
}

Também é importante problematizar sobre a qualidade dos cursos, e não apenas considerar a expansão da oferta. Em 2013, o Exame Nacional de Desempenho dos Estudantes (Enade), que atribui indicadores que vão de 1 a 5 , avaliou cursos da área da saúde. Na UFG, do total de 18 cursos avaliados, apenas dois obtiveram conceito $5(11,1 \%)$, sendo eles os seguintes cursos: Enfermagem (Goiânia) e Medicina (Goiânia). Obtiveram nota 4 os seguintes cursos: Agronomia (Goiânia), Farmácia (Goiânia), Medicina Veterinária (Goiânia), Nutrição (Goiânia), Odontologia (Goiânia), Zootecnia (Goiânia), Enfermagem (Catalão), Agronomia (Jataí), Enfermagem (Jataí), Medicina Veterinária (Jataí) e Zootecnia (Jataí), os quais representem $61,1 \%$ do total de cursos (INEP, 2015a). Em 2013, o percentual de cursos bem avaliados na UFG foi $72,2 \%$.

Em 2014, o Enade avaliou cursos nas áreas de engenharia e licenciaturas. Nesse ano, na UFG, 65 cursos foram avaliados, e os que obtiveram nota 5 no Enade foram: Arquitetura e Urbanismo (Goiânia), Ciência da Computação (Goiânia), Engenharia Civil (Goiânia), Engenharia Mecânica (Goiânia) e Física - bacharelado (Goiânia), os quais representem $7,7 \%$ do total. Já os que obtiveram conceito 4 
foram: Artes Visuais - licenciatura (Goiânia), Ciência Sociais - bacharelado e licenciatura (Goiânia), Engenharia Florestal (Goiânia), Geografia - licenciatura (Goiânia), Pedagogia (Goiânia), Ciências Sociais - licenciatura (Catalão), Engenharia Civil (Catalão), Ciências Biológicas - licenciatura (Jataí), Engenharia Florestal (Jataí), Física - licenciatura (Jataí), Geografia - licenciatura (Jataí), Química - licenciatura (Jataí), $18,7 \%$ do total (INEP, 2015b). Portanto, apenas $26,4 \%$ dos cursos da universidade avaliados no período foram bem avaliados.

Em 2015, foram avaliados pelo Enade os bacharelados nas áreas de Ciências Sociais Aplicadas, Ciências Humanas e Áreas afins e os Eixos Tecnológicos em Gestão e Negócios, Apoio Escolar, Hospitalidade e Lazer, Produção Cultural e Design. Na UFG, em 2015, apenas cinco dos cursos avaliados obtiveram nota máxima, 5, sendo eles os seguintes: Direito (Jataí), Administração (Goiânia), Psicologia (Goiânia), Ciências Contábeis (Goiânia) e Comunicação Social habilitação em Publicidade e Propaganda (Goiânia). Com resultado também satisfatório, com nota 4, estiveram os seguintes cursos: Administração (Catalão), Psicologia (Jataí), Direito (Goiânia), Ciências Econômicas (Goiânia) e Jornalismo (Goiânia) (UFG, 2017).

No Brasil, em 2015, do total de cursos avaliados pelo Enade, 3,4\% tiveram conceito $1 ; 26,9 \%$ conceito $2 ; 42,7 \%$ conceito $3 ; 18,8 \%$ conceito $4 ; 5 \%$ conceito 5 ; e $3,2 \%$ não tiveram conceito. Significa que $73 \%$ dos cursos avaliados são cursos com baixa qualidade (INEP, 2017b). Desse modo, a despeito da pouca quantidade de cursos com notas 5 e 4 , a UFG se destaca entre as universidades bem avaliadas.

No ranking das 50 melhores universidades do país em 2015, segundo o MEC, a UFG ocupa a $34^{a}$ posição. Entre as instituições do estado de Goiás, a UFG foi a primeira colocada. Esse resultado foi baseado no Índice Geral de Cursos (IGC), que consiste na média ponderada das notas dos cursos de graduação e pós-graduação de cada instituição. $O$ índice da instituição é 4, e o máximo possível de se atingir é 5 . No Brasil, há 26 instituições com IGC 5 (1\%), 13 delas instituições públicas (1 estadual e 12 federais) e 13 instituições privadas. 352 instituições com índice 4 (15,2\%), 1442 com índice 3 (62,8\%), 339 com índice 2 (14,6\%), 11 com índice 1 $(0,4 \%)$ e $124(5,2 \%)$ sem conceito. 


\section{O INGRESSO}

O gráfico abaixo apresenta a evolução do número de vagas ofertadas e de alunos ingressantes na universidade.

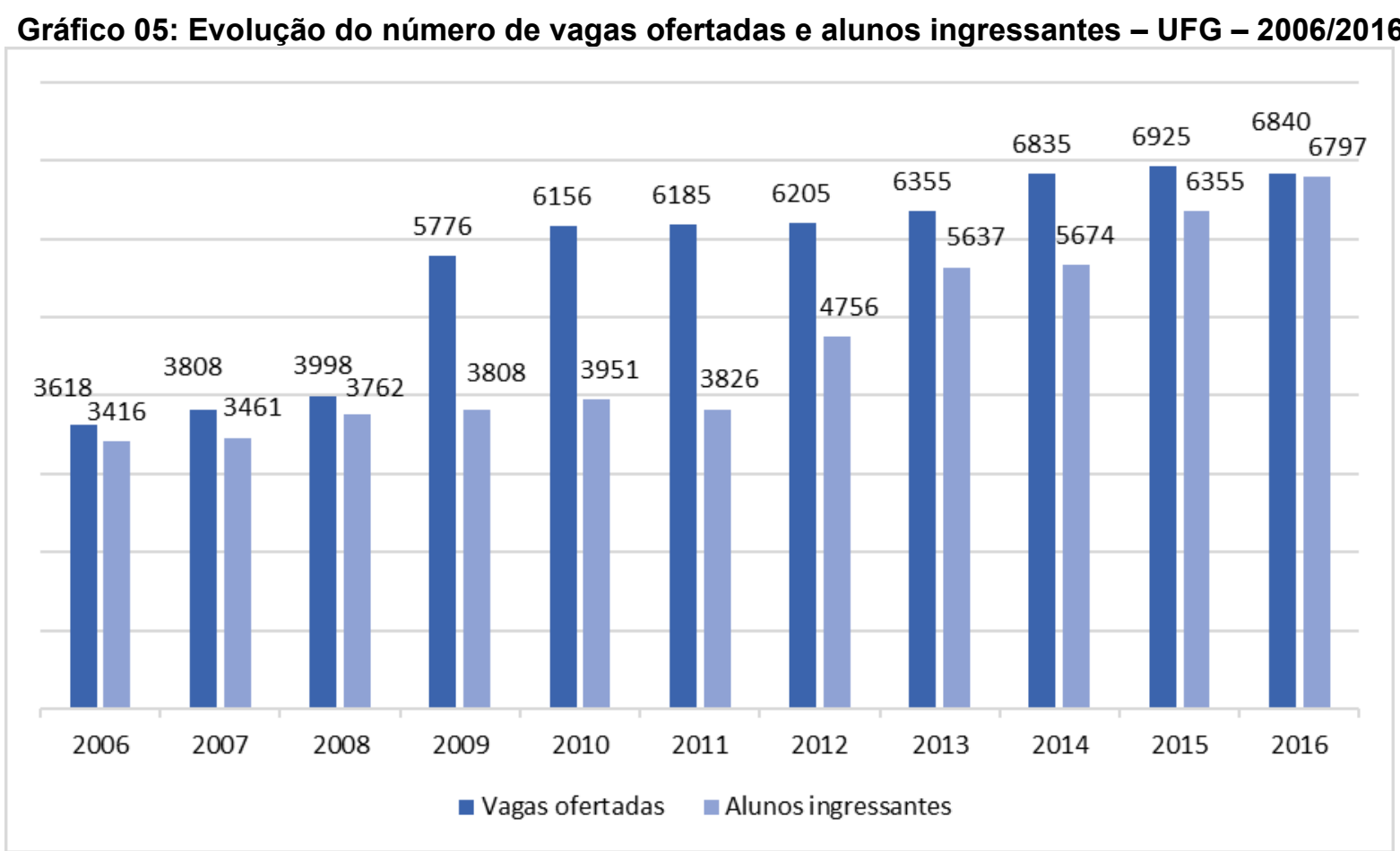

Fonte: A autora.

De 2006 a 2016, o número de vagas ofertadas na UFG passou de 3.618 para 6.840 , um aumento de $89,05 \%$. Mas a maior variação em relação à oferta ocorreu a partir de 2009, em decorrência da adesão da UFG ao Reuni. De 2008 para 2009, a oferta passou de 3.998 para 5.776 vagas, um crescimento de 44,5\%. De 2009 a 2016, o número de vagas passou de 5.776 para 6.797 , um crescimento de $17,7 \%$, portanto, menor do que o ocasionado pela grande expansão promovida pelo Reuni em 2009, no início do programa.

Já o número de ingressantes passou de 3.416 para 6.797 , um crescimento de 98,97\%. A maior taxa de variação, entretanto, ocorreu de 2011 para 2013, quando o número de ingressantes passou de 3.826 para 5.637 , um aumento de $47,3 \%$. De 2013 a 2016, o aumento continuou, mas de forma menos intensa, passando de 
5.637 para 6.797 , um crescimento de 20,6\%. Depreende-se, pois, que em razão do aumento de vagas ofertadas, cresceu, também, o número de ingressantes.

Na compreensão de Costa e Dias (2015),

\begin{abstract}
A ampliação do acesso ao nível superior no Brasil pode ser considerado uma grande conquista social. Atualmente, camadas alijadas desta possibilidade têm acesso ao primeiro diploma de curso superior de sua geração. Encontra-se em transformação a realidade de um ES [ensino superior] marcado pelo prestígio, reservado a camadas privilegiadas e, portanto, criteriosamente selecionadas (COSTA; DIAS, 2015, p. 59).
\end{abstract}

Portanto, há um forte viés de justiça social relacionado à expansão da oferta de cursos, vagas e ingressantes na educação superior brasileira, e também no caso específico da UFG.

Para ocupar as vagas ofertadas pela UFG, o processo seletivo adotado é o Sistema de Seleção Unificada (Sisu). Anteriormente a 2011, havia apenas o processo seletivo da instituição. A partir de 2015, a UFG adotou totalmente ao Sisu como mecanismo de acesso à educação superior, acreditando no benefício de ampliar o acesso, visto que as provas do processo seletivo, antes feitas em Goiânia, Goiás, Catalão e Jataí, deixariam de existir, passando-se a adotar o Exame Nacional do Ensino Médio (Enem), quem é realizado em 56 cidades do estado de Goiás.

Além disso, ao adotar o Enem, tem-se uma taxa de inscrição única para o candidato, que pode concorrer em mais de uma instituição com uma única inscrição. Assim, a oportunidade de fazer a prova aumenta. No mais, acreditava-se que o Sisu propiciaria a diminuição das vagas ociosas na universidade, além de promover a distribuição mais igualitária da ocupação das vagas, principalmente as licenciaturas.

A partir da adoção do Sisu na UFG, a maior parte das vagas passou a ser ocupada por estudantes ingressantes por esse sistema, como demonstrado no gráfico a seguir: 
Gráfico 06: Evolução do número de alunos por modalidade de ingresso - UFG - 2011/2016

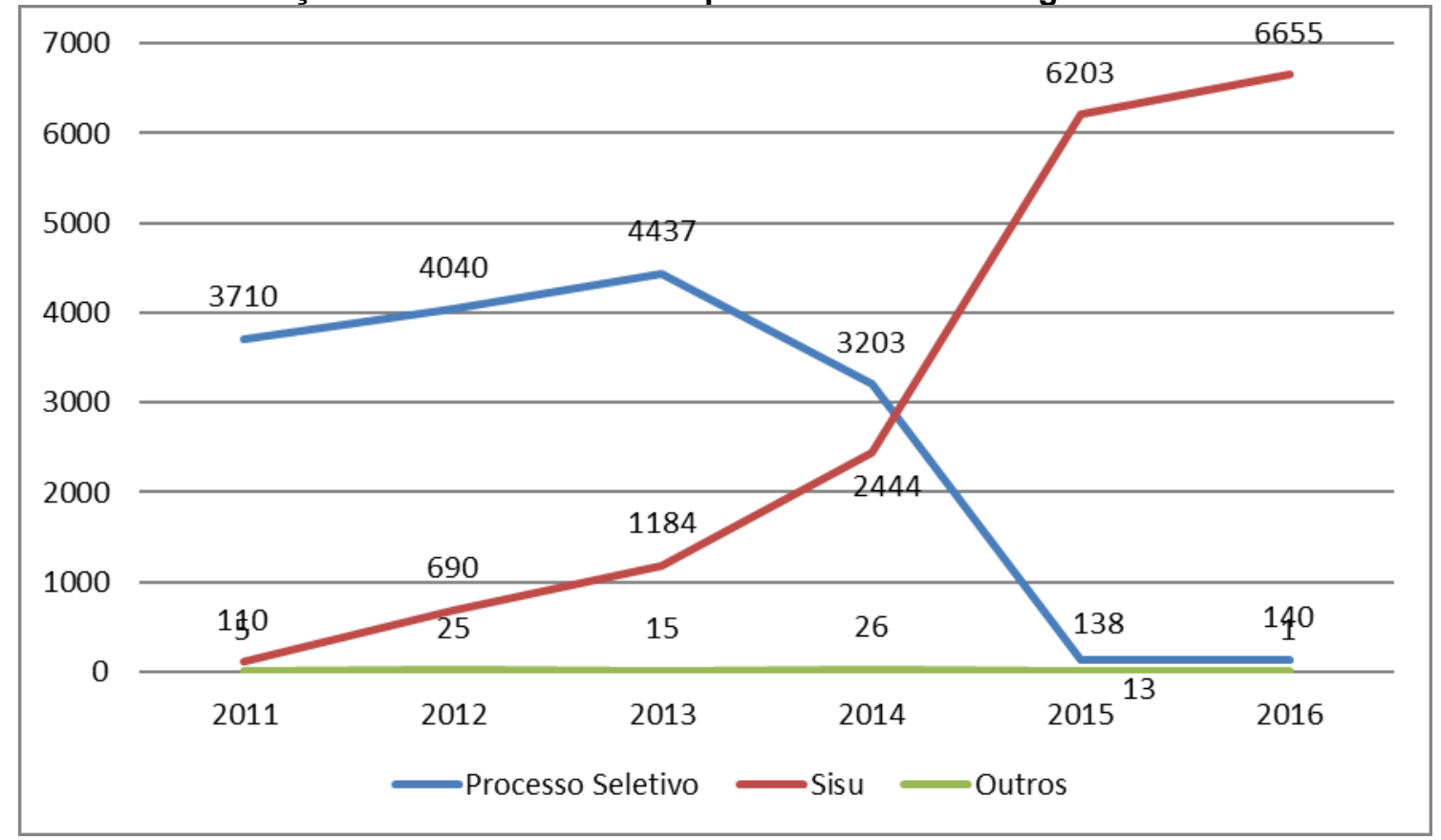

Fonte: A autora.

Pelo exposto no gráfico acima, constata-se que, de 2011 até 2014, a maior parte das vagas da UFG foi ocupada por estudantes que ingressavam pelo processo seletivo tradicional. Em 2011, isso ocorreu com 97\% das vagas, em 2012 com 85\% e em 2013 com 78,6\%. Em 2014, a relação entre vagas ocupadas por meio de ingresso por processo seletivo já foi bastante inferior aos anos anteriores, de apenas 56,5\%, aproximando-se da taxa de ocupação pelo Sisu, que foi de 43,1\%. Em 2015 e 2016 a taxa de ocupação de vagas pelo Sisu foi de 97,5\% e 97,8\%, respectivamente, ao passo que a ocupação de vagas pelo processo seletivo da instituição foi de apenas $2,2 \%$ e $2,1 \%$, respetivamente. Nesse período, portanto, houve uma estabilização em termos de estudantes por modalidade de ingresso.

O que aconteceu na UFG foi uma tendência nacional. Enquanto em 2010, em todo o Brasil, foram ofertadas apenas 47.913 vagas pelo Sisu, em 2016 esse número passou para 228.071, o que corresponde a um aumento de $376 \%$. Essa evolução também acompanhou o número de inscrições, que passou de 1.664 .532 para 5.275.613 no mesmo período, um crescimento de $216,9 \%$. Como a elevação percentual do número de vagas foi maior que o aumento das inscrições, a relação de candidatos por vaga, que era de 34,7 em 2010, passou para 23,1 em 2016. 
Vale destacar que, em 2016, a UFG foi a sexta instituição de educação superior brasileira em número de inscrições, com o total de 141.372 inscritos pelo Sisu, ficando atrás apenas da Universidade Federal de Minas Gerais (UFGM) (195.634), Universidade Federal do Ceará (UFCE) (160.474), Universidade Federal de Pernambuco (UFPE) (157.428), Universidade Federal do Rio de Janeiro (UFRJ) (155.540) e Instituto Federal de Educação, Ciência e Tecnologia de São Paulo (IFSP) (153.929). Em 2017, a universidade subiu uma posição no ranking, e foi a quinta instituição com maior número de inscrições do Sisu (130.007), ficando atrás apenas da UFMG (171.825), da UFPE (144.322), da UFCE (140.849) e da Universidade Federal do Maranhão (UFMA) (131.899).

Porém, a partir da adesão ao Sisu, é necessário problematizar a não ocupação das vagas ofertadas na primeira chamada. Estudo realizado por Nogueira et al. (2017) na UFMG mostra que, a despeito do crescimento do número de candidatos inscritos para a universidade, aumentou significativamente o número de aprovados que não efetivaram suas matrículas, o que levou a universidade a ter que realizar diversas outras chamadas, atrasando a ocupação inicial das vagas. Essa é a mesma realidade da UFG, que normalmente realiza várias chamadas na tentativa de preencher as vagas ofertadas.

Na UFG, no Sisu para ingresso em 2017, os cursos com maior número de candidatos por vaga foram os seguintes:

Quadro 01: Cursos com maior quantitativo de candidatos por vaga no Sisu - UFG - 2017

\begin{tabular}{|l|c|c|c|c|}
\hline \multicolumn{1}{|c|}{ Curso } & Grau & Regional & $\begin{array}{c}\text { Modalidade de } \\
\text { concorrência }\end{array}$ & $\begin{array}{c}\text { Candidatol } \\
\text { vaga }\end{array}$ \\
\hline Medicina & Bacharelado & Jataí & Ampla concorrência & 88,60 \\
\hline Direito & Bacharelado & Goiânia & Lei de cotas & 77,83 \\
\hline Enfermagem & Bacharelado & Goiânia & Lei de cotas & 66,12 \\
\hline Medicina & Bacharelado & Jataí & Lei de cotas & 62,40 \\
\hline Direito & Bacharelado & Goiânia & Lei de cotas & 61,13 \\
\hline Odontologia & Bacharelado & Goiânia & Lei de cotas & 54,57 \\
\hline Medicina & Bacharelado & Goiânia & Ampla concorrência & 53,87 \\
\hline Direito & Bacharelado & Goiânia & Ampla concorrência & 53,00 \\
\hline Psicologia & ABI & Goiânia & Lei de cotas & 52,94 \\
\hline Medicina & Bacharelado & Goiânia & Lei de cotas & 52,89 \\
\hline $\begin{array}{l}\text { Arquitetura e } \\
\text { Urbanismo }\end{array}$ & Bacharelado & Goiás & Lei de cotas & 51,00 \\
\hline
\end{tabular}




\begin{tabular}{|c|c|c|c|c|}
\hline Administração & Bacharelado & Goiânia & Lei de cotas & 50,24 \\
\hline Ciências Contábeis & Bacharelado & Goiânia & Lei de cotas & 49,40 \\
\hline Ciências Contábeis & Bacharelado & Goiânia & Ampla concorrência & 49,10 \\
\hline Nutrição & Bacharelado & Goiânia & Lei de cotas & 48,19 \\
\hline $\begin{array}{l}\text { Arquitetura e } \\
\text { Urbanismo }\end{array}$ & Bacharelado & Goiás & Ampla concorrência & 47,13 \\
\hline Enfermagem & Bacharelado & Goiânia & Ampla concorrência & 45,24 \\
\hline Educação Física & Bacharelado & Goiânia & Lei de cotas & 44,95 \\
\hline Educação Física & Licenciatura & Goiânia & Lei de cotas & 44,75 \\
\hline Direito & Bacharelado & Goiânia & Ampla concorrência & 42,30 \\
\hline Psicologia & Bacharelado & Jataí & Lei de cotas & 42,15 \\
\hline Administração & Bacharelado & Goiânia & Ampla concorrência & 41,78 \\
\hline Fisioterapia & Bacharelado & Jataí & Lei de cotas & 41,50 \\
\hline Pedagogia & Licenciatura & Goiânia & Lei de cotas & 40,40 \\
\hline Psicologia & $\mathrm{ABI}$ & Goiânia & Ampla concorrência & 40,18 \\
\hline Odontologia & Bacharelado & Goiânia & Ampla concorrência & 39,03 \\
\hline Direito & Bacharelado & Goiás & Lei de cotas & 38,30 \\
\hline Medicina Veterinária & Bacharelado & Goiânia & Lei de cotas & 36,67 \\
\hline Direito & Bacharelado & Jataí & Lei de cotas & 36,67 \\
\hline Biomedicina & Bacharelado & Goiânia & Lei de cotas & 36,37 \\
\hline Nutrição & Bacharelado & Goiânia & Ampla concorrência & 36,00 \\
\hline Medicina Veterinária & Bacharelado & Goiânia & Ampla concorrência & 35,00 \\
\hline Fisioterapia & Bacharelado & Jataí & Ampla concorrência & 35,00 \\
\hline Educação Física & Bacharelado & Goiânia & Ampla concorrência & 34,90 \\
\hline Psicologia & Bacharelado & Jataí & Ampla concorrência & 34,35 \\
\hline Enfermagem & Bacharelado & Catalão & Lei de cotas & 34,13 \\
\hline Farmácia & Bacharelado & Goiânia & Lei de cotas & 34,11 \\
\hline Zootecnia & Bacharelado & Goiânia & Lei de cotas & 33,65 \\
\hline Pedagogia & Licenciatura & Goiânia & Lei de cotas & 31,29 \\
\hline Jornalismo & Bacharelado & Goiânia & Lei de cotas & 30,96 \\
\hline Educação Física & Licenciatura & Goiânia & Ampla concorrência & 30,55 \\
\hline Ciências Contábeis & Bacharelado & Goiânia & Lei de cotas & 30,30 \\
\hline
\end{tabular}

Fonte: A autora.

Os cinco cursos com maior concorrência pelo Sisu no Brasil foram: Medicina (47,6 candidatos por vaga), Educação Física (35,67), Direito (35,2), Administração $(29,7)$ e Pedagogia $(26,41)$. Todos esses cursos estão entre os mais concorridos também da UFG, o que sinaliza uma tendência de alta procura por determinadas carreiras, com aquelas de grande prestígio social, como Medicina e Direito. Também vale destacar que, entre os dez cursos com maior número de inscrições no Sisu de 2017, a UFG ocupou a oitava e nona posição, justamente com os cursos de Direito (10.913 inscritos) e Medicina (10.402 inscritos). 
Já os cursos com menor concorrência na UFG foram os seguintes:

Quadro 02: Cursos com menor quantitativo de candidatos por vaga no Sisu - UFG - 2017

\begin{tabular}{|c|c|c|c|c|}
\hline Curso & Grau & Regional & $\begin{array}{l}\text { Modalidade de } \\
\text { concorrência }\end{array}$ & $\begin{array}{c}\text { Candidatol } \\
\text { vaga }\end{array}$ \\
\hline Letras - Linguística & Bacharelado & Goiânia & Ampla concorrência & 4,40 \\
\hline Física & Licenciatura & Catalão & Ampla concorrência & 5,16 \\
\hline Química & Licenciatura & Goiânia & Ampla concorrência & 5,29 \\
\hline Engenharia Física & Bacharelado & Goiânia & Ampla concorrência & 5,50 \\
\hline Geografia & Bacharelado & Goiânia & Ampla concorrência & 5,53 \\
\hline Ciências Biológicas & Licenciatura & Catalão & Ampla concorrência & 5,80 \\
\hline $\begin{array}{l}\text { Letras - Português e } \\
\text { Inglês }\end{array}$ & Licenciatura & Catalão & Ampla concorrência & 5,80 \\
\hline Física & Licenciatura & Goiânia & Ampla concorrência & 6,00 \\
\hline $\begin{array}{l}\text { Letras - Português e } \\
\text { Inglês }\end{array}$ & Licenciatura & Catalão & Lei de cotas & 6,36 \\
\hline Química & Bacharelado & Jataí & Ampla concorrência & 7,00 \\
\hline Matemática Industrial & Bacharelado & Catalão & Ampla concorrência & 7,04 \\
\hline Física & Licenciatura & Goiânia & Lei de cotas & 7,08 \\
\hline Química & Bacharelado & Goiânia & Ampla concorrência & 7,09 \\
\hline Matemática & Licenciatura & Jataí & Ampla concorrência & 7,23 \\
\hline Ciências Biológicas & Bacharelado & Jataí & Ampla concorrência & 7,25 \\
\hline Matemática & Licenciatura & Catalão & Lei de cotas & 7,28 \\
\hline Ciências Biológicas & Bacharelado & Catalão & Ampla concorrência & 7,40 \\
\hline Química & Bacharelado & Jataí & Ampla concorrência & 7,40 \\
\hline Letras - Inglês & Licenciatura & Jataí & Lei de cotas & 7,47 \\
\hline Matemática & Licenciatura & Catalão & Ampla concorrência & 7,52 \\
\hline Química & $\mathrm{ABI}$ & Catalão & Ampla concorrência & 7,56 \\
\hline Física & Bacharelado & Goiânia & Ampla concorrência & 7,75 \\
\hline Ciência da Computação & Bacharelado & Jataí & Lei de cotas & 7,80 \\
\hline Letras - Inglês & Licenciatura & Jataí & Ampla concorrência & 7,80 \\
\hline Matemática Industrial & Bacharelado & Catalão & Lei de cotas & 7,84 \\
\hline Ciências Sociais & $\mathrm{ABI}$ & Catalão & Ampla concorrência & 7,87 \\
\hline História & Licenciatura & Jataí & Ampla concorrência & 7,88 \\
\hline Ciências Econômicas & Bacharelado & Goiânia & Ampla concorrência & 7,90 \\
\hline Física & Licenciatura & Catalão & Lei de cotas & 7,92 \\
\hline Geologia & Bacharelado & Goiânia & Ampla concorrência & 7,95 \\
\hline Matemática & Licenciatura & Jataí & Lei de cotas & 7,96 \\
\hline
\end{tabular}

Fonte: A autora.

Dos 42 cursos com maior número de candidatos por vaga em 2017, apenas quatro eram da licenciatura (9,5\%). Já dos 31 cursos com menor relação de candidatos por vaga, 15 eram de licenciatura (48,4\%). Logo, é notório que esses são os menos demandados pelos estudantes no momento do processo para ingresso na universidade. Mesmo assim, é interessante salientar que, no período em questão, não houve curso com menor número de candidatos que o de vagas ofertadas. 
Apesar desse caso de baixa demanda, no caso específico da UFG, é interessante observar que, em 2017, dos 28 cursos que não tiveram suas vagas totalmente ocupadas, apenas 6 eram licenciatura $(21,4 \%)$; os demais eram cursos de bacharelado (75\%), e um deles grau não definido (3,6\%). Por assim ser, depreendese que, por mais que as licenciaturas sejam cursos pouco concorridos na universidade, a totalidade de vagas na grande maioria dos mesmos é totalmente preenchida.

Considerando a concorrência dos cursos, a tendência é acreditar que, para os cursos mais concorridos, a nota mínima para ingresso seja maior. Porém, na UFG, dos cursos com maior quantitativo de candidatos, apenas 5 estiveram entre os com maior nota mínima para ingresso, que foram: Direito, Odontologia, Medicina, Psicologia e Medicina Veterinária, como evidenciado no gráfico abaixo. Os outros cursos mais concorridos da instituição tiveram notas para ingresso dentro da média geral da universidade. Em contrapartida, cursos que estão entre os menos concorridos, como Engenharia Física e História, estiveram entre aqueles com maior nota mínima para ingresso, como se vê a seguir:

Gráfico 07: Cursos com maior nota mínima para ingresso pelo Sisu - UFG - 2017

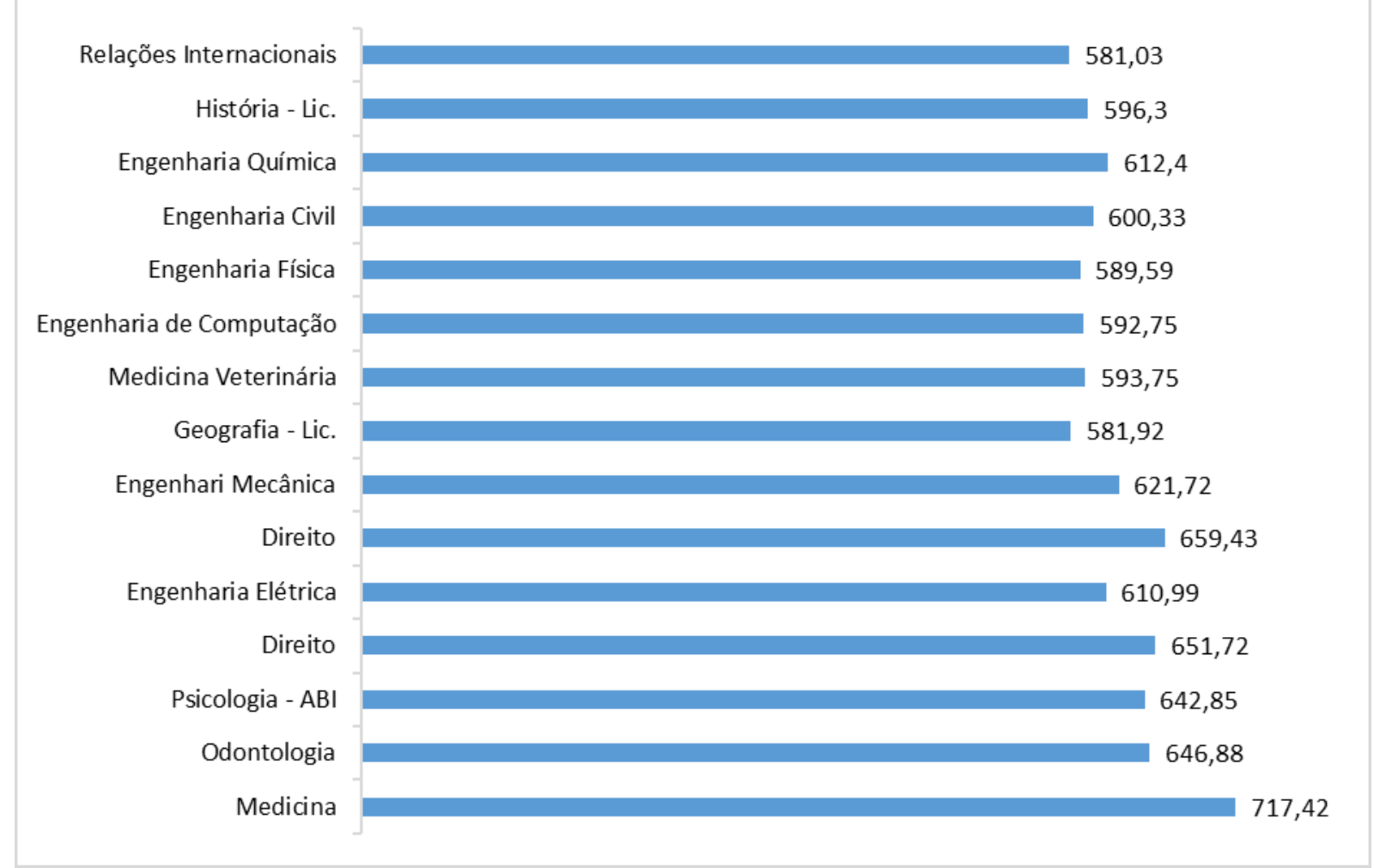

Fonte: A autora. 
Já os cursos com menor nota mínima para ingresso em 2017 foram os seguintes:

Gráfico 08: Cursos com menor nota mínima para ingresso pelo Sisu - UFG - 2017

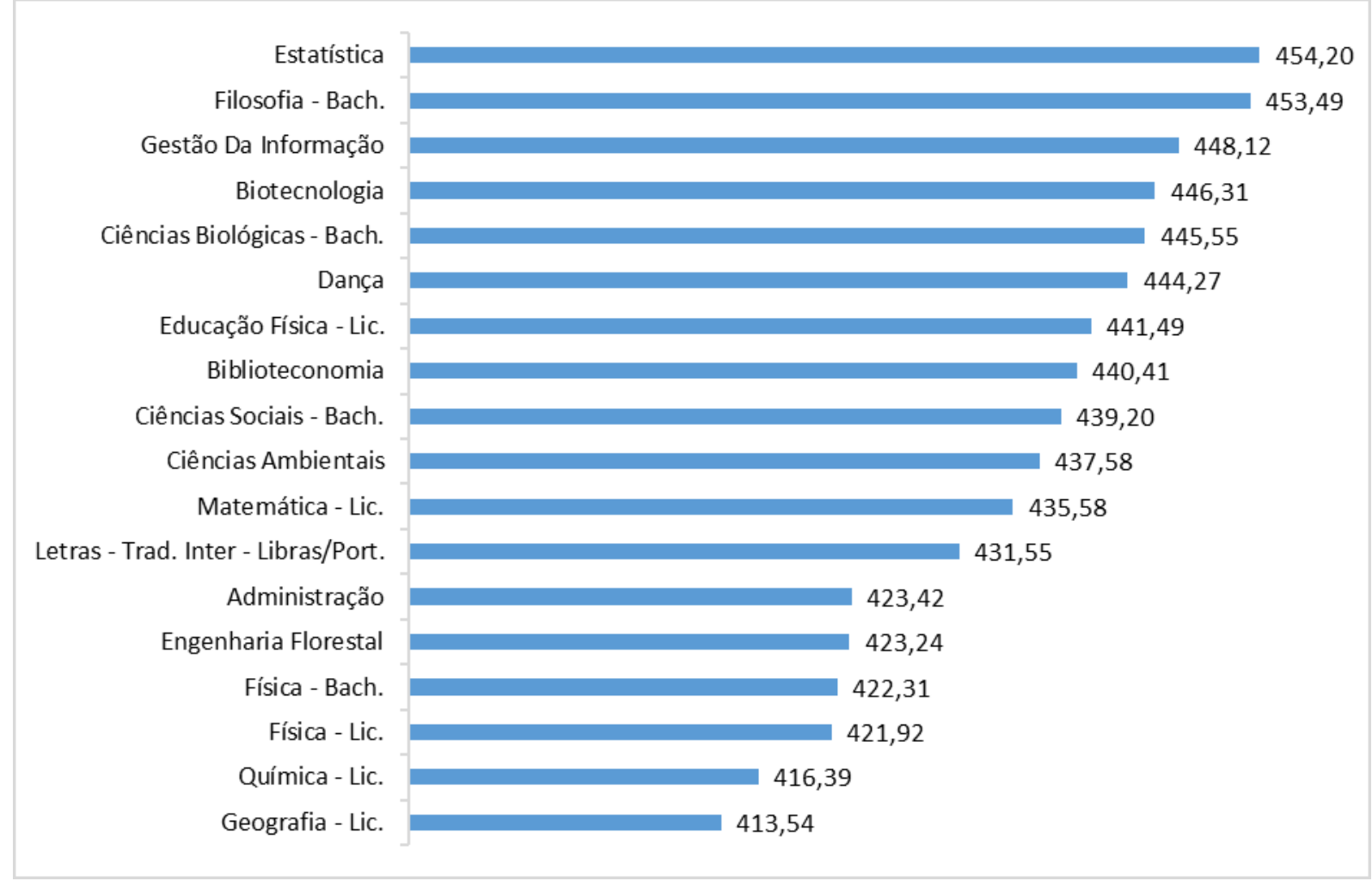

Fonte: A autora.

Dos cursos com menor nota mínima para ingresso, alguns deles estão entre os menos concorridos da instituição, como Física, Química, Geografia, Ciências Biológicas e Matemática.

Considerando o total de cursos ofertados pela UFG, a média da nota mínima para ingresso foi 517,79 pontos. No Brasil, no Enem de 2016, a média dos participantes na área de Ciências Humanas e suas Tecnologias foi 533,5 pontos; em Ciências da Natureza e suas Tecnologias 477,1 pontos; em Linguagens e Códigos e suas tecnologias 520,5 pontos; e em Matemática e suas tecnologias 489,5 pontos. No geral, a média dos participantes foi 505,15 pontos (INEP, 2017a). Portanto, a nota mínima média para ingresso na UFG em 2017 foi muito próxima à média geral dos participantes do Enem em 2016. Significa, pois, que os estudantes da UFG estão na média geral, ou seja, não se destacam entre os alunos que possuem notas 
elevadas no Enem. Não se pode desconsiderar a exceção de alguns cursos, como os mencionados acima, que demandaram notas mínimas mais elevadas, acima da média.

Também no panorama nacional, Medicina ocupou sete posições do ranking das maiores notas de corte para ingresso pelo Sisu em 2017 , sendo de 831,3 pontos para cotas na Universidade de São Paulo (USP), 829,6 pontos na Universidade de Brasília (UnB), 826,2 na Universidade Federal do Paraná (UFPR), 822,31 na Universidade Federal do Rio de Janeiro (UFRJ), 818,5 na Universidade Federal de Santa Catarina (UFSC), 817,1 na Universidade Estadual de Minas Gerais (UEMG) e 814,1 pontos para cotistas na UnB. Já o curso de Direito, que na UFG teve a quarta maior nota de ingresso, no panorama nacional teve a maior nota, de 837,8 pontos na Universidade Federal Fluminense (UFF).

\section{CONSIDERAÇÕES FINAIS}

A UFG é a única universidade federal do estado de Goiás, e uma das mais importantes do Centro-Oeste e também do país. Ela está entre as mais almejadas pelos estudantes brasileiros, e alguns de seus cursos, como Direito e Medicina, estão entre os mais concorridos do país. No mais, é uma instituição que se destaca pela qualidade dos seus cursos, que são normalmente bem avaliados no Enade.

A partir da adesão ao Reuni, a instituição passou por um processo de expansão significativo, o que permitiu a incorporação de um número de expressivo de estudantes, tanto na regional da Capital, quanto nas regionais situadas no interior do estado. Com isso, a universidade adquire relevância pela ampliação das oportunidades educacionais, com também pela interiorização, que é uma de suas marcas.

Entretanto, principalmente a partir da adesão da universidade ao Sisu, fica o desafio do preenchimento das vagas de forma mais eficiente. Do modo como está organizado atualmente, o Sisu demanda várias chamadas para ter suas vagas ocupadas. Com isso, muitos alunos acabam entrando tardiamente, quando o semestre letivo já está em andamento. Isso pode levar à dificuldade de adaptação 
do ingressante na universidade, bem como ocasionar a elevação do número de reprovações no primeiro semestre do curso, em razão da dificuldade que o aluno pode ter de acompanhar uma disciplina já em curso. No mais, é preciso se ater para o fato de que tanto a dificuldade de adaptação quanto a reprovação excessiva são fatores que levam à evasão.

Portanto, assegurado o acesso à universidade, é preciso cuidar para que os estudantes que ingressam permaneçam e construam uma trajetória acadêmica satisfatória. Nesse sentido, é importante o desenvolvimento de ações voltadas para o acolhimento desse alunado, cada vez mais heterogêneo, que enfrenta problemas desde a adaptação ao ambiente universitário, passando pelo baixo desempenho nas disciplinas, dificuldades de ordem socioeconômica, e mais. Sendo assim, a partir do ingresso, é elementar que a gestão da universidade se ocupe da manutenção do corpo discente, desde a matrícula até a conclusão do curso.

\section{CHAIANE DE MEDEIROS ROSA}

Doutora em Educação Escolar pela Universidade Estadual Paulista - UNESP campus Araraquara. Mestra em Educação pela Universidade Federal de Goiás -UFG - campus Catalão.

\section{RICARDO RIBEIRO}

Doutor em Educação pela Universidade de São Paulo - USP. Atualmente é professor assistente doutor da Universidade Estadual Paulista Júlio de Mesquita Filho, sendo também vice-coordenador do Programa de Pós-Graduação em Educação Escolar e vice-chefe do Departamento de Ciências da Educação deste mesma universidade.

\section{REFERÊNCIAS}

BARROS, Aparecida da Silva Xavier. Expansão da educação superior no Brasil: limites e possibilidades. Educ. Soc., Campinas, v. 36, n. 131, p. 361-390, abr./jun. 2015.

BRASIL. Ministério da Educação. Secretaria de Educação Superior. $A$ democratização e expansão da educação superior no país - 2003-2014. Brasília: MEC/Sesu, 2015. Disponível em: 
http://portal.mec.gov.br/index.php?option=com docman\&view=download\&alias=1676 2-balanco-social-sesu-2003-2014\&ltemid=30192. Acesso em: 17 abr. 2018.

CASSELL, Catherine; SYMON, Gillian. Qualitative methods in organizational research. London: Sage Publications, 1994.

COSTA, Silvio Luiz; DIAS, Sonia Maria Barbosa. A permanência no ensino superior e as estratégias institucionais de enfrentamento da evasão. Jornal de Políticas Educacionais, v. 9, n. 17 e 18, p. 51-60, 2015.

FONSECA, João José Saraiva. Metodologia da pesquisa científica. Fortaleza: UEC, 2002.

INEP. Enade 2013. Universidade Federal de Goiás. Brasília: MEC/Inep, 2015a.

Enade 2014. Relatório de IES. Universidade Federal de Goiás. Brasília:

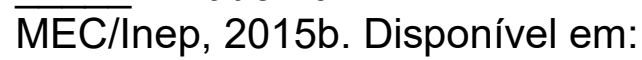
https://cavi.prodirh.ufg.br/up/65/o/Goi\%C3\%A2nia.pdf. Acesso em: 31 ago. 2017. . Enem 2016. Resultado Individual. Brasília: MEC/Inep, 2017a. $\overline{2017 b}$. . Indicadores de qualidade da educação superior 2015. Brasília: MEC/Inep, Sinopse Estatística da Educação Superior - 2015. Brasília: Inep, 2017c.

NOGUEIRA, Cláudio Marques Martins et al. Promessas e limites: o Sisu e sua implantação na Universidade Federal de Minas Gerais. Educação em Revista, Belo Horizonte, n. 33, p. 1-31, 2017.

RICHARDSON, Roberto Jarry. Pesquisa social: métodos e técnicas. São Paulo: Atlas, 1989.

ROSA, Chaiane de Medeiros. A Rede Federal de Educação Profissional, Cientifica e Tecnológica no contexto das políticas de educação superior: as particularidades do IF Goiano - Campus Urutaí. Tese de Doutorado. Faculdade de Ciência, 2016.

ROSA, Chaiane de Medeiros; GONÇALVES, Ana Maria. A dimensão social da expansão da educação superior no Brasil. Cadernos de Pesquisa: Pensamento Educacional, Curitiba, v.11, n. 27, p. 176-192, jan./abr. 2016.

UFG. Plano de Reestruturação e Expansão da Universidade Federal de Goiás. Goiânia: UFG, 2008. . Plano de Desenvolvimento Institucional 2011-2015. Goiânia: UFG, 2010. 
Atos de Pesquisa em Educação - ISSN 1809-0354

Blumenau, v.14, n.2, p.545-567, mai./ago. 2019

DOI: http://dx.doi.org/10.7867/1809-0354.2019v14n2p545-567

Assessoria de Comunicação. Cursos da UFG obtêm nota 5 no Enade. Goiânia: UFG/Ascom, 09/03/2017. Disponível em: https://www.ufg.br/n/95227cursos-da-ufg-obtem-nota-5-no-enade. Acesso em: 31 ago. 2017. 